\title{
High prevalence of primary adrenal insufficiency in Zellweger spectrum disorders
}

\author{
Kevin Berendse ${ }^{1,2}$, Marc Engelen ${ }^{1}$, Gabor E Linthorst ${ }^{3}$, AS Paul van Trotsenburg ${ }^{4}$ and Bwee Tien Poll-The ${ }^{1 *}$
}

\begin{abstract}
Zellweger spectrum disorders are a group of autosomal recessive disorders characterized by impaired peroxisome functions. The clinical spectrum is broad, ranging from the classical most severe Zellweger syndrome to patients with a relatively mild phenotype. Treatment options are limited to symptomatic and supportive therapy. During routine follow-up we discovered patients with asymptomatic primary adrenal insufficiency. It is important to detect impaired adrenal function because it has treatment implications. Primary adrenal insufficiency was found in 7/24 patients examined, with 4/7 being asymptomatic. Systematic evaluation of adrenal function, through a Synacthen test, should be included in the clinical management of these patients.
\end{abstract}

Keywords: Adrenal insufficiency, peroxisomal disorders, Very long-chain fatty acids, Zellweger spectrum disorders, X-linked adrenoleukodystrophy

\section{Background}

Peroxisomal disorders are a group of genetic disorders with impairment in one or more peroxisomal functions [1]. The peroxisomal disorders are divided into two major categories: (1) the peroxisome biogenesis disorders with multiple metabolic abnormalities (e.g. Zellweger spectrum disorders (ZSDs), OMIM \#601539), and (2) the disorders with a deficiency of a single peroxisomal enzyme or transporter (e.g. X-linked adrenoleukodystrophy (X-ALD), OMIM \#300100). X-ALD is characterized by accumulation of very long-chain fatty acids (VLCFA, $\geq \mathrm{C} 22: 0$ ), due to an impaired peroxisomal beta-oxidation. Adrenal insufficiency, either subclinical or overt as well as the late onset form, is found in the majority of X-ALD patients, and frequently precede the neurological symptoms giving rise to the "Addison-only" phenotype [2].

Adrenal insufficiency may also occur in ZSD patients. The ZSDs are autosomal recessive disorders, characterized by impairment of multiple peroxisomal functions due to mutations in different PEX genes [1]. Clinically, the ZSDs constitute a spectrum of disease severity, ranging from severe (Zellweger syndrome (ZS), OMIM \#214100) to attenuated phenotypes, like infantile Refsum disease (IRD,

\footnotetext{
*Correspondence: b.t.pollthe@amc.uva.nl

'Department of Paediatric Neurology, Emma Children's Hospital/Academic Medical Centre, Meibergdreef 9, Amsterdam 1105 AZ, The Netherlands Full list of author information is available at the end of the article
}

OMIM \#266510) [3]. Most ZSD patients have disorders in the milder end of the spectrum and should be follow-up for symptomatic and supportive therapy. Among others, these patients have elevated concentrations of VLCFA and bile acid intermediates in plasma.

During routine follow-up we discovered impaired adrenocortical function in some of our ZSD patients. Because most of the patients have severe neurological symptoms, primary adrenal insufficiency might be easily overlooked. Untreated adrenocortical dysfunction may have serious consequences, while treatment is available [4]. To estimate the prevalence of adrenocortical dysfunction and, with that, to determine whether or not routine testing in these patients is useful, we assessed the adrenal function in our patients with a ZSD.

\section{Findings}

The characteristics of the patients are presented in Table 1. Twenty-four patients with a ZSD, age ranging from 2.834.6 years (median 15.4 years) underwent a Synacthen test (Additional file 1). An inadequate increase in plasma cortisol concentrations was found in 7/24 (29\%) patients and an adequate response in cortisol $(>550 \mathrm{nmol} / \mathrm{l})$ was seen in the others. Four of the 7 patients (57\%) diagnosed with primary adrenal insufficiency, were asymptomatic. The 3 patients with clinical manifestations of adrenal insufficiency presented with muscle and/or joint pain, vomiting 
Table 1 Clinical, laboratory and genetic findings in 24 patients with a mild ZSD

\begin{tabular}{|c|c|c|c|c|c|c|c|c|c|c|c|c|}
\hline & \multirow[t]{3}{*}{ Case } & \multirow{3}{*}{$\begin{array}{l}\text { Present } \\
\text { age, } y\end{array}$} & \multirow{3}{*}{$\begin{array}{l}\text { Age at } \\
\text { test, } y\end{array}$} & \multirow{3}{*}{$\begin{array}{l}\text { C26:0 in plasma } \\
\text { around time of } \\
\text { Synacthen } \\
(0.45-1.32)\end{array}$} & \multirow{3}{*}{$\begin{array}{l}\text { Average C26:0 } \\
\text { in plasma* }\end{array}$} & \multirow{3}{*}{$\begin{array}{l}\text { Basal } \\
\text { ACTH } \\
(1-55)\end{array}$} & \multirow{3}{*}{$\begin{array}{l}\text { Basal cortisol } \\
/ 30^{\prime} / 60^{\prime} \text { after } \\
\text { injection } \\
(>550)\end{array}$} & \multirow{3}{*}{$\begin{array}{l}\text { Clinical } \\
\text { symptoms }\end{array}$} & \multirow{3}{*}{$\begin{array}{l}\text { Plasma renin } \\
\text { levels }\end{array}$} & \multicolumn{2}{|l|}{ Phenotype } & \multirow[t]{3}{*}{ PEX mutation ${ }^{1}$} \\
\hline & & & & & & & & & & Communication & $\begin{array}{l}\text { Motor } \\
\text { function }\end{array}$ & \\
\hline & & & & & & & & & & & & \\
\hline \multirow{24}{*}{ Adrenal insuf. } & 1 & 6.6 & 5.9 & 10.28 & $7.75 ; 1.57$ & 100 & $203 / 275$ / 290 & asymp & 5.5 & ++ & ++ & PEX1 c.2528G > A \\
\hline & 2 & 4.4 & 2.8 & 7 & $6.28 ; 1.13$ & 180 & $201 / 254 / 260$ & asymp & 5.5 & - & - & PEX1 c.2528G > A \\
\hline & 3 & 20.4 & 18.5 & 4.63 & $\mathbf{5 . 4 5} ; 2.47$ & $\#$ & $112 / 273 / 306$ & asymp & 5.1 & - & - & $\begin{array}{l}\text { PEX1 c. } 2528 \mathrm{G}>\mathrm{A} / \\
\text { c.2097insT }\end{array}$ \\
\hline & 4 & 8.4 & 3.0 & 4.43 & 4.93; 0.99 & \# & $200 / 260 / 190$ & v & $>576$ & - & + & PEX1 c. $2528 \mathrm{G}>\mathrm{A}$ \\
\hline & 5 & 14.5 & 12.2 & 3.38 & $\mathbf{3 . 8 7} ; 1.37$ & 5140 & $185 / 203 / 167$ & hp & 4.9 & - & ++ & PEX1 c.2528G > A \\
\hline & 6 & 24.7 & 22.9 & 2.73 & $2.90 ; 0.78$ & 66 & $156 / 203 / 202$ & $\mathrm{hp}, \mathrm{mp}$ & 2.7 & ++ & - & PEX26 c.292C > T \\
\hline & 7 & 11.8 & 10.1 & 2.28 & $2.40 ; 0.34$ & 390 & $535 / 477$ / 524 & asym & 6.3 & + & ++ & PEX1 c.2528G > A \\
\hline & 8 & 24.3 & 24.2 & 2.44 & $4.91 ; 3.98$ & 53 & $428 / 734 / 781$ & & & + & - & PEX1 c.2528G > A \\
\hline & 9 & 24.2 & 23.8 & 2.79 & 4.13; 1.10 & 44 & 441 / 624 / 624 & & & + & - & $\begin{array}{l}\text { PEX1 c.2528G }>\mathrm{A} / \\
\text { unknown }\end{array}$ \\
\hline & 10 & 6.8 & 5.8 & 3.38 & $3.94 ; 1.06$ & nd & 370 / nd / 990 & & & - & - & PEX1 c.2528G > A \\
\hline & 11 & 10.3 & 9.1 & 3.78 & $3.94 ; 1.15$ & 17 & $125 / 458 / 607$ & & & - & - & $\begin{array}{l}\text { PEX1 c. } 2528 \mathrm{G}>\mathrm{A} / \\
\text { c.2097insT }\end{array}$ \\
\hline & 12 & 8.7 & 8.2 & 3.21 & $3.77 ; 0.69$ & 35 & 85 / 425 / 557 & & & ++ & ++ & PEX1 c.2528G > A \\
\hline & 13 & 29.8 & 29.4 & 3.7 & $3.71 ; 0.78$ & 27 & $902 / 1079$ / 1090 & & & ++ & + & $\begin{array}{l}\text { PEX1 c.2528G > A } \\
\text { unknown }\end{array}$ \\
\hline & 14 & 22.8 & 22.2 & 3.51 & $2.69 ; 1.28$ & 26 & $306 / 629$ / 701 & & & ++ & ++ & PEX1 c.2528G > A \\
\hline & 15 & 17.3 & 16.9 & 2.35 & $2.45 ; 0.46$ & 20 & 270 / 601 / 698 & & & ++ & ++ & PEX1 c.2528G > A \\
\hline & 16 & 35.0 & 34.6 & 3.31 & $2.17 ; 0.67$ & 9 & 342 / 624 / 648 & & & ++ & ++ & PEX1 C.2528G > A \\
\hline & 17 & 19.0 & 18.6 & 1.63 & $1.82 ; 0.46$ & 25 & $430 / 668 / 778$ & & & ++ & ++ & PEX1 c.2528G > A \\
\hline & 18 & 8.1 & 7.5 & 1.24 & $1.78 ; 0.18$ & 44 & $571 / 726 / 690$ & & & ++ & ++ & PEX1 c.2528G > A \\
\hline & 19 & 11.8 & 11.2 & 1.2 & $1.53 ; 0.35$ & 33 & 189 / $601 / 687$ & & & ++ & ++ & PEX1 c.2528G > A \\
\hline & 20 & 8.3 & 7.6 & 0.81 & $1.50 ; 0.74$ & 34 & 588 / 910 / 993 & & & ++ & ++ & $\begin{array}{l}\text { PEX10 c. } 1 \mathrm{~A}>\mathrm{G} / \\
\text { c.199C > T }\end{array}$ \\
\hline & 21 & 29.7 & 29.3 & 1.38 & 1.38 & nd & $215 / 620 / 705$ & & & ++ & ++ & PEX11ß c.64C > T \\
\hline & 22 & 15.4 & 14.6 & 1.8 & $1.38 ; 0.27$ & 18 & $227 / 519 / 618$ & & & ++ & ++ & PEX26 c.292C > T \\
\hline & 23 & 30.3 & 29.9 & 1.98 & $1.35 ; 0.39$ & 19 & $274 / 579 / 709$ & & & ++ & ++ & PEX1 c.2528G > A \\
\hline & 24 & 16.7 & 16.1 & 1.28 & $1.34 ; 0.34$ & 17 & $356 / 593 / 665$ & & & ++ & ++ & PEX1 c.2528G > A \\
\hline
\end{tabular}

${ }^{*}=$ average

immunoreactivity caused by hemolysis. Phenotype: $-=$ no communication or wheelchair bound, $+=$ non-verbal communication or walk with support, $++=$ verbal communication or independent walking. ${ }^{1}=$ PEX mutations are homozygous if one sequence is given. 

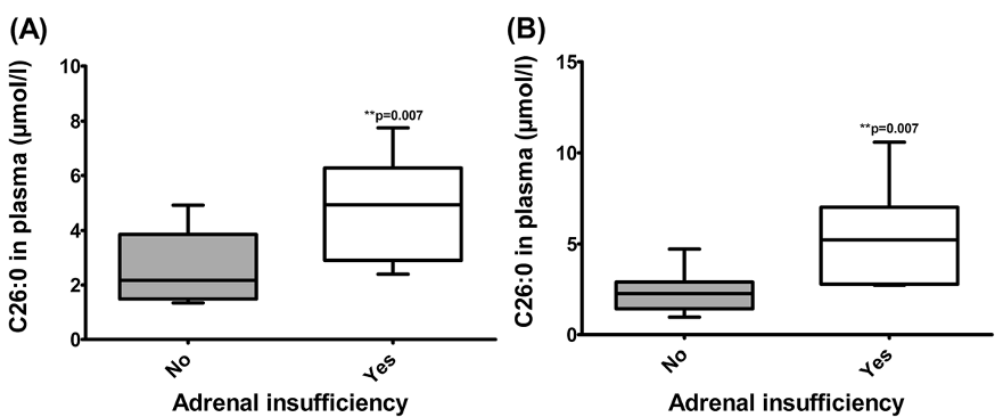

Figure 1 Boxplots showing median, range and interquartile range of the VLCFA concentrations in plasma of the patients with or without a primary adrenal insufficiency. (A) Mean of all VLCFA concentrations in time per patient (B) VLCFA concentrations around time of ACTH stimulation test. Statistical analyses were performed with a Mann-Whitney $U$ test.

or hyperpigmentation. We found one patient (number 4) with additional adrenocortical dysfunction (i.e. hyperkalemia) as a sign of hypoaldosteronism [5]. Plasma renin was normal in 6/7 patients. Oral hydrocortisone (and fludrocortisone in patient 4) treatment was started in all diagnosed patients.

To obtain a framework for comparing severity of the clinical phenotype and adrenal insufficiency we delineated three categories on the basis of the degree of communication and motor function (Table 1). Elevated plasma VLCFA (C26:0) concentrations were present in 22/24, with an abnormal C26:0/C22:0 ratio in 24/24. Baseline plasma cortisol concentrations ranged from 85-902 nmol/l (median $272 \mathrm{nmol} / \mathrm{l}$ ) and baseline plasma ACTH concentrations from 9-390 ng/l (median $33 \mathrm{ng} / \mathrm{l}$ ), with one patient having $5140 \mathrm{ng} / \mathrm{l}$.

We found a correlation between the average concentrations of C26:0 and C26:0 levels around the time of the ACTH test in plasma and the occurrence of an adrenal insufficiency (Figure 1). There was no correlation between age, sex, PEX mutation or phenotypic severity and adrenal dysfunction.

\section{Discussion}

In 1984, Govaerts et al. reported the occurrence of primary adrenal insufficiency in a small series of severe ZS patients [6]. The prevalence in ZSD patients with attenuated phenotypes has not yet been investigated. In this study we found a high prevalence of primary adrenal insufficiency in a cohort of ZSD patients.

The pathophysiological mechanism underlying the primary (usually only glucocorticoid) adrenocortical dysfunction in ZSDs and X-ALD is unknown. Several studies, including studies on post mortem material, suggest that elevated (i.e. toxic) concentrations of VLCFA cause adrenal cell dysfunction leading to decreased cortisol response and thus adrenal insufficiency [7-13]. We found a correlation between the occurrence of an adrenal insufficiency and the concentration of $\mathrm{C} 26: 0$ in plasma. Because plasma C26:0 concentrations can fluctuate over time due to for instance diet, we used the average of all C26:0 values over time for each patient (Figure 1). We observed no adrenal insufficiency when the average concentration of C26:0 in plasma was below $2.40 \mu \mathrm{mol} / \mathrm{l}$, while all patients with an average C26:0 $>4.91 \mu \mathrm{mol} / \mathrm{l}$ had adrenocortical dysfunction (Table $1, n=4$ ). Due to the single time point data, small size of our cohort and large variation in age, the importance of the correlation between VLCFA concentrations in plasma and adrenal insufficiency should not be overrated and needs confirmation in future studies.

In this study we found a high prevalence (29\%) of primary adrenal dysfunction in ZSD patients, with some being asymptomatic at the time of the test. We therefore recommend that all ZSD patients should be screened for adrenal insufficiency during routine follow-up, in order to initiate appropriate therapy (Additional file 2).

\section{Additional files}

\section{Additional file 1: Supplementary methods.}

Additional file 2: Recommendations on the management of primary adrenal insufficiency.

\section{Abbreviations}

IRD: Infantile Refsum disease; VLCFA: Very long chain fatty acids; X-ALD: X-linked adrenoleukodystrophy; ZS: Zellweger syndrome; ZSD: Zellweger spectrum disorder.

\section{Competing interests}

The authors declare that they have no competing interests.

\section{Authors' contributions}

KB, ME, BTPT: Conception and design, data acquisition, analysis, and interpretation, manuscript draft and revision. GEL: Data acquisition, interpretation, manuscript draft and revision. ASPVT: Design, interpretation, manuscript draft and revision. All authors read and approved the final manuscript.

\section{Acknowledgments}

The authors thank the patients and their families for their cooperation and the referring physicians, especially Prof. B.H.R. Wolffenbuttel (University Medical Centre Groningen, The Netherlands); Dr. M.E.J. Wegdam-den Boer (Medical Spectrum Enschede, The Netherlands); Drs. A.B.C. Roeleveld-Versteegh 

We thank Dr. F. Vaz and Dr. H.R. Waterham (Academic Medical Centre, The Netherlands) for providing biochemical and genetic data. This work is supported financially by the Foundations "Stichting Steun Emma" and "Metakids", Amsterdam, The Netherlands.

\section{Author details}

'Department of Paediatric Neurology, Emma Children's Hospital/Academic Medical Centre, Meibergdreef 9, Amsterdam 1105 AZ, The Netherlands. 2Laboratory for Genetic Metabolic Diseases, Emma Children's Hospital/ Academic Medical Centre, Meibergdreef 9, Amsterdam 1105 AZ, The Netherlands. ${ }^{3}$ Department of Endocrinology and Metabolism, Emma Children's Hospital/Academic Medical Centre, Meibergdreef 9, Amsterdam $1105 \mathrm{AZ}$, The Netherlands. ${ }^{4}$ Department of Paediatric Endocrinology, Emma Children's Hospital/Academic Medical Centre, Meibergdreef 9, Amsterdam 1105 AZ, The Netherlands.

Received: 26 June 2014 Accepted: 18 August 2014

Published: 2 September 2014

\section{References}

1. Waterham HR, Ebberink MS: Genetics and molecular basis of human peroxisome biogenesis disorders. Biochim Biophys Acta 2012, 1822:1430-1441.

2. Engelen $M$, Kemp S, de Visser M, van Geel BM, Wanders RJA, Aubourg P, Poll-The BT: X-linked adrenoleukodystrophy (X-ALD): clinical presentation and guidelines for diagnosis, follow-up and management. Orphanet $J$ Rare Dis 2012, 7:51.

3. Goldfischer S, Moore CL, Johnson AB, Spiro AJ, Valsamis MP, Wisniewski HK, Ritch RH, Norton WT, Rapin I, Gartner LM: Peroxisomal and Mitochondrial Defects in the Cerebro-Hepato-Renal Syndrome. Science 1973, 182:62-64.

4. Arlt W, Allolio B: Adrenal insufficiency. Lancet 2003, 361:1881-1893.

5. Marik PE: Mechanisms and clinical consequences of critical illness associated adrenal insufficiency. Curr Opin Crit Care 2007, 13:363-369.

6. Govaerts L, Monnens L, Melis T, Trijbels F: Disturbed adrenocortical function in cerebro-hepato-renal syndrome of Zellweger. Eur J Pediatr 1984, 143:10-12.

7. Govaerts L, Sippell WG, Monnens L: Further analysis of the disturbed adrenocortical function in the cerebro-hepato-renal syndrome of Zellweger. J Inherit Metab Dis 1989, 12:423-428.

8. Powers JM, Schaumburg HH, Johnson AB, Raine CS: A correlative study of the adrenal cortex in adreno-leukodystrophy-evidence for a fatal intoxication with very long chain saturated fatty acids. Invest Cell Pathol 1980, 3:353-376.

9. Knazek RA, Rizzo WB, Schulman JD, Dave JR: Membrane microviscosity is increased in the erythrocytes of patients with adrenoleukodystrophy and adrenomyeloneuropathy. J Clin Invest 1983, 72:245-248.

10. Whitcomb RW, Linehan WM, Knazek RA: Effects of long-chain, saturated fatty acids on membrane microviscosity and adrenocorticotropin responsiveness of human adrenocortical cells in vitro. J Clin Invest 1988, 81:185-188.

11. Van Den Branden C, Collumbien R, Roels F, Dacremont G, Roels H: Altered Adrenocortical Response under the Influence of Experimentally Increased Serum Very Long Chain Fatty Acids in Rats. Pathol Res Pract 1993, 189:558-562

12. Goldfischer S, Powers JM, Johnson AB, Axe S, Brown FR, Moser HW: Striated adrenocortical cells in cerebro-hepato-renal (Zellweger) syndrome. Virchows Arch A Pathol Anat Histopathol 1983, 401:355-361.

13. Powers JM, Schaumburg HH: Adreno-leukodystrophy (sex-linked Schilder's disease). A pathogenetic hypothesis based on ultrastructural lesions in adrenal cortex, peripheral nerve and testis. Am J Pathol 1974, 76:481-491.

doi:10.1186/s13023-014-0133-5

Cite this article as: Berendse et al:: High prevalence of primary adrenal insufficiency in Zellweger spectrum disorders. Orphanet Journal of Rare Diseases 2014 9:133.

\section{Submit your next manuscript to BioMed Central and take full advantage of:}

- Convenient online submission

- Thorough peer review

- No space constraints or color figure charges

- Immediate publication on acceptance

- Inclusion in PubMed, CAS, Scopus and Google Scholar

- Research which is freely available for redistribution

Submit your manuscript at www.biomedcentral.com/submit
Biomed Central 